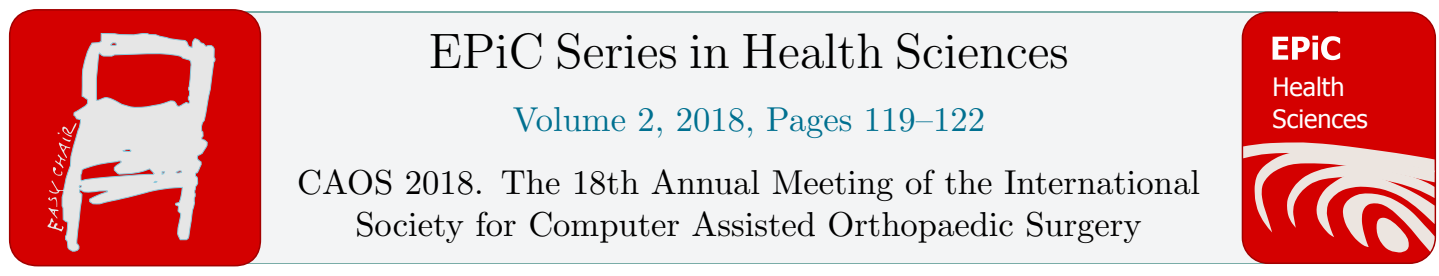

\title{
A Retrospective Analysis of S2 Iliosacral Screw Fixation Using Robot-Assisted Navigation for Unstable Pelvic Injuries and Sacral Dysmorphism: a Report of 16 Cases
}

Wang Junqiang $\mathrm{MD}^{1}$, Han Wei $\mathrm{MD}^{2}$, Zhang Teng $\mathrm{MD}^{2}$, Su Yonggang $\mathrm{MD}^{2}$, Wu Xinbao $\mathrm{MD}^{3}$, Wang Manyi $\mathrm{MD}^{3}$

${ }^{1}$ Department of Orthopedic Trauma, Beijing Jishuitan Hospital, Beijing 100035, China,drw-jq1997@163.com

${ }^{2 .}{ }^{3}$ Department of Orthopedic Trauma, Beijing Jishuitan Hospital, Beijing 100035, China

\section{INTRODUCTION}

Percutaneous sacroiliac (SI) screw fixation under fluoroscopic guidance for unstable posterior pelvic ring fractures has been shown to be a safe method. It is becoming increasingly popular worldwide, due to its advantages of minimal invasion to compromised soft tissue, limited blood loss, and decreased infection rates, compared to conventional open techniques[1-3]. Placing iliosacral screws into the first sacral vertebral body (S1) is the preferred method of fixation, but S1 dysmorphism may influence even rule out S1 fixation. In these clinical situations, fixation into the second sacral vertebral body (S2) has been recommended[4, 5]. However, there are few researches concerning how to place S2 screw safety when S1 dysmorphism occurs. Incorrect placement of SI screws may result in implant-related and neurovascular complications[6], therefore it's urgent to find a safe and effective method to solve this problem. TiRobot ${ }^{\mathrm{TM}}$ is an orthopaedic surgery robot which can be used for SI screw fixation which has shown accuracy in cadaver and cohort studies[7]. This study is designed to analyse of the accuracy of S2 screws using robot-assisted navigation.

\section{MATERIALS AND METHODS}

A retrospective analysis of 16 patients admitted and managed by S2 screw fixation for unstable pelvic fractures was carried out for evaluation of its efficacy and safety. all patients with pelvic ring disruptions and sacral dysmorphism were evaluated 
radiographically and S2 screws were placed using a robot-assisted navigation technique. Screw position, according to the classifications used by Gras and Marintschev, was assessed using postoperative computed tomography. Fisher's exact probabilities test was used to analyse the screws' positions. Surgical time after reduction of the pelvis, insertion time for guide wire, number of guide wire attempts, and radiation exposure without pelvic reduction were also assessed.

\section{RESULTS}

The excellent and good rate of screw placement was $100 \%$. The fluoroscopy time after pelvic reduction was $7(7,9)$ seconds. The operation time after reduction of the pelvis was $29(27,33)$. Time for guide wire insertion was $2.0(2,2)$ minutes. The number of guide wire attempts was $0.0(0,0)$. No postoperative complications or revisions were reported.

\section{Illustrative clinical case}

A 21-year-old male patient sustained pelvic fractures in a car accident. The preoperative X-ray film and CT scan showed a C3-type injury involving bilateral sacral fractures and lumbarization was discovered (Figure 1). Seven days after injury, he underwent surgery and two screws ware symmetrically placed in S2 vertebral body using TiRobot ${ }^{\mathrm{TM}}$. The postoperative X-ray image and CT scan showed satisfactory reduction and fixation of the pelvic (Figure 2). Both of Screws were in the bone channel and there were no postoperative complications including nerve palsy and revision.

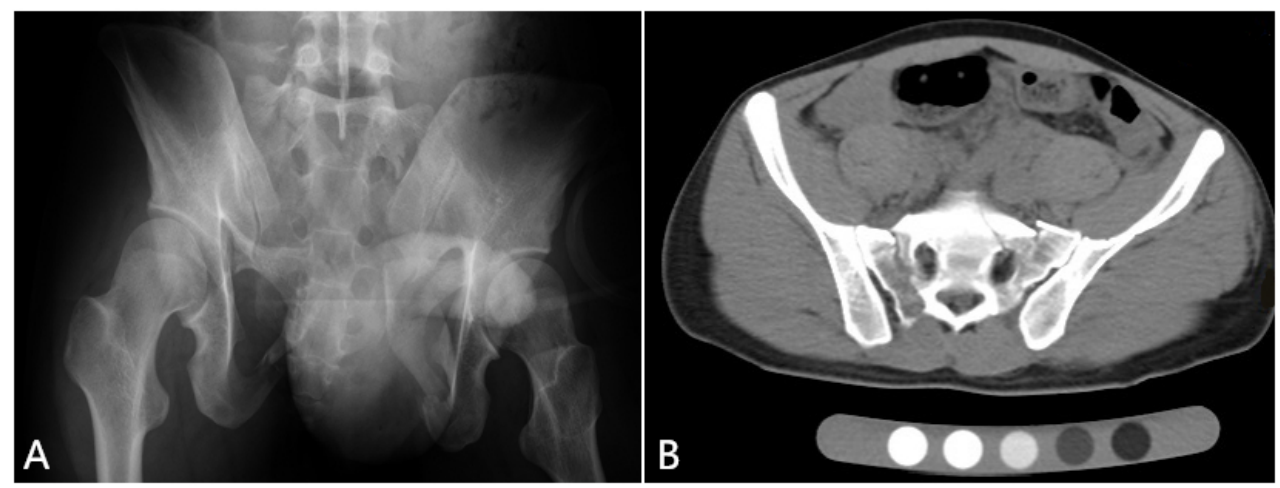

Figure 1: preoperative X-ray film and CT scan 


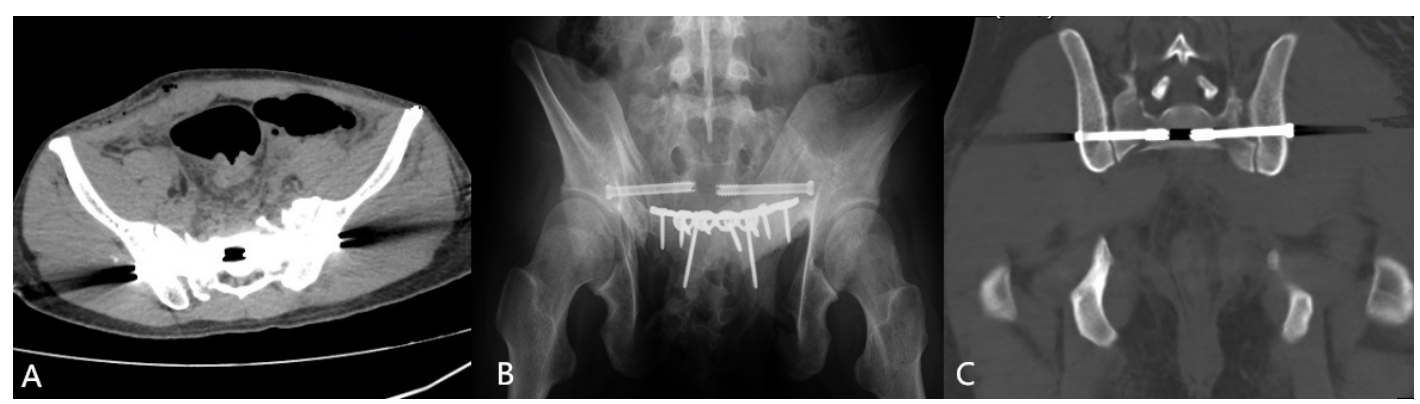

Figure 2: Postoperative X-ray film and CT scan

\section{DISCUSSION}

Existing literatures[8-10] discussed either free hand S2 screw placement under perspective or computer-assisted S2 screw placement using optical navigation. This study is the first one to apply robot-assisted navigation. Robot-assisted navigation, which can do not only intraoperative real-time monitoring and preoperative planning, but also auxiliary operation with mechanical arm, is more intelligent and minimally invasive than other computer assisted orthopaedic surgery. It is likely to be a kind of standard of minimally invasive technique in the future.

\section{REFERENCES}

1. Schweitzer D, Zylberberg A, Cordova M, Gonzalez J. Closed reduction and iliosacral percutaneous fixation of unstable pelvic ring fractures. Injury. 2008;39(8):869-74. doi:10.1016/j.injury.2008.03.024.

2. Routt ML, Jr., Simonian PT, Mills WJ. Iliosacral screw fixation: early complications of the percutaneous technique. Journal of orthopaedic trauma. 1997;11(8):584-9.

3. Routt ML, Jr., Nork SE, Mills WJ. Percutaneous fixation of pelvic ring disruptions. Clinical orthopaedics and related research. 2000(375):15-29.

4. Gardner MJ, Morshed S, Nork SE, Ricci WM, Chip Routt ML, Jr. Quantification of the upper and second sacral segment safe zones in normal and dysmorphic sacra. Journal of orthopaedic trauma. 2010;24(10):622-9. doi:10.1097/BOT.0b013e3181cf0404.

5. Miller AN, Routt ML, Jr. Variations in sacral morphology and implications for iliosacral screw fixation. The Journal of the American Academy of Orthopaedic Surgeons. 2012;20(1):8-16. doi:10.5435/JAAOS-20-01-008.

6. Templeman D, Schmidt A, Freese J, Weisman I. Proximity of iliosacral screws to neurovascular structures after internal fixation. Clinical orthopaedics and related research. 1996(329):194-8.

7. Wang JQ, Wang Y, Feng Y, Han W, Su YG, Liu WY et al. Percutaneous Sacroiliac Screw Placement: A Prospective Randomized Comparison of Robot- 
assisted Navigation Procedures with a Conventional Technique. Chinese medical journal. 2017;130(21):2527-34. doi:10.4103/0366-6999.217080.

8. Osterhoff G, Ossendorf C, Wanner GA, Simmen HP, Werner CML. Percutaneous iliosacral screw fixation in S1 and S2 for posterior pelvic ring injuries: technique and perioperative complications. Archives of Orthopaedic \& Trauma Surgery. 2011;131(6):809-13.

9. Sugita S, Takeshita K, Ooshima Y, Chikuda H, Nakamura K. The S2 Iliac Screw Technique with a CT Navigation System : A Case Report. Journal of Spine Research. 2010;1:2040-4.

10. Behrendt D, Mütze M, Steinke H, Koestler M, Josten C, Böhme J. Evaluation of 2D and $3 \mathrm{D}$ navigation for iliosacral screw fixation. International Journal of Computer Assisted Radiology \& Surgery. 2012;7(2):249-55. 